Universidad de Lima

Facultad de Comunicación

Carrera de Comunicación

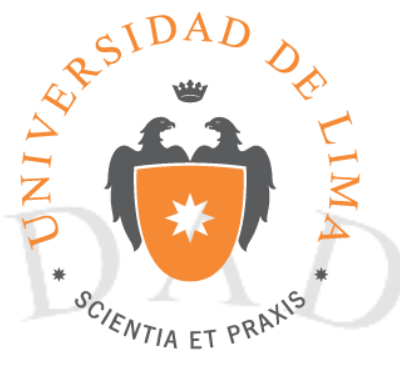

\title{
LA EDUCOMUNICACIÓN COMO UN MODELO PARA EDUCAR: EL CASO DEL PROYECTO FOTOGRÁFICO PINHOLE VERTE MIRARTE
}

Trabajo de investigación para optar la licenciatura en Comunicación

CAROL CRISTINA VENTURA BRONCALES

Código 20091206

Asesor

Carlos Vidal Rivadeneyra Olcese

\author{
Lima - Perú
}

Septiembre de 2016 


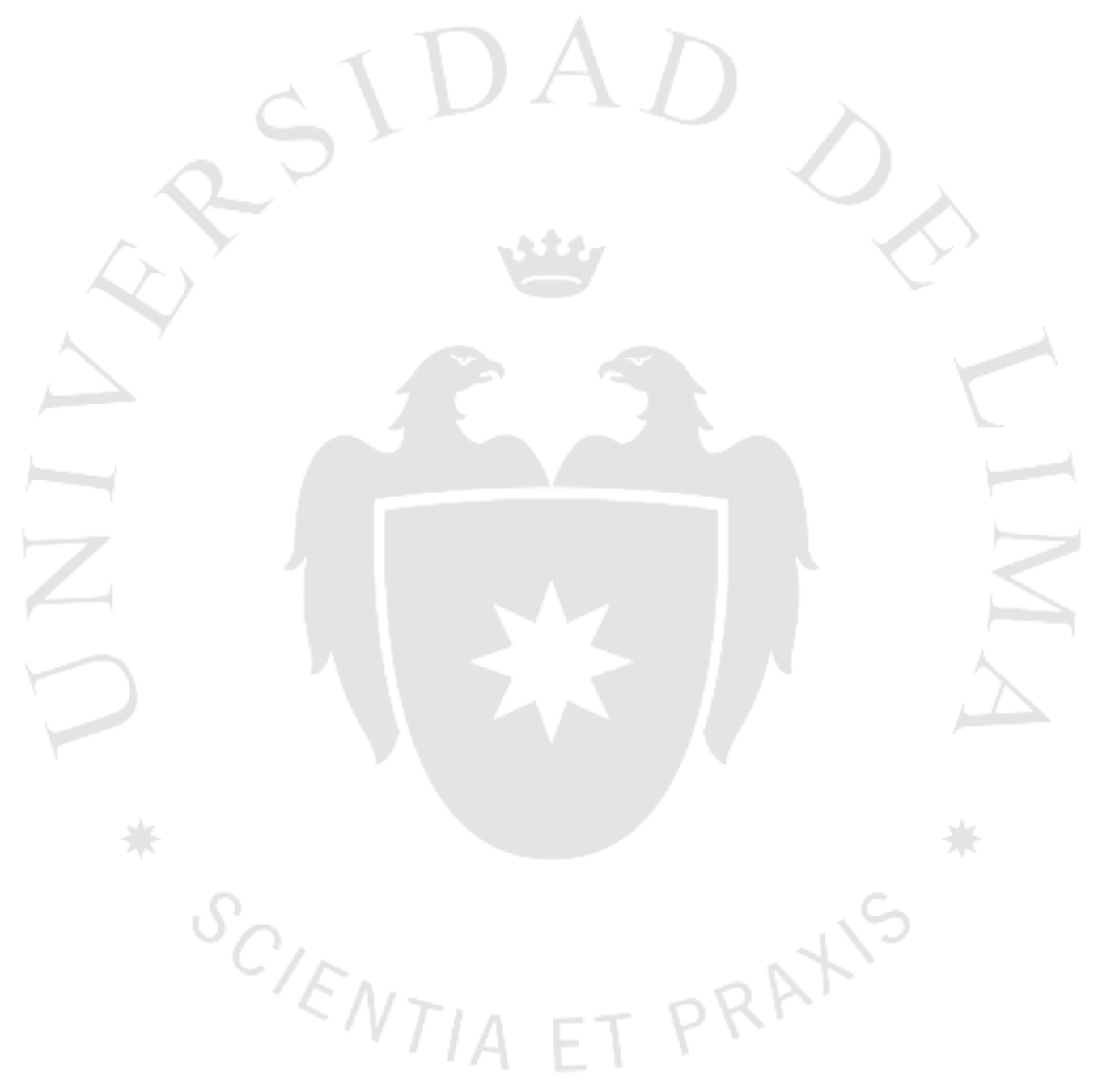




\section{LA EDUCOMUNICACIÓN COMO UN MODELO PARA EDUCAR: EL CASO DEL PROYECTO FOTOGRÁFICO PINHOLE VERTE MIRARTE}




\section{RESUMEN}

El presente artículo aspira dar a conocer los aportes educomunicativos del Proyecto Fotográfico Pinhole Verte MirArte, cuyo principal objetivo fue reconocer y despertar la mirada interna de niños, niñas y adolescentes de bajos recursos por medio del concepto y la práctica de la fotografía pinhole. Se trata de emplear la fotografía como una herramienta didáctica, la cual busca desarrollar la inteligencia racional y emotiva, así como el pensamiento crítico y la reflexión sobre la imagen. A través de un trabajo cualitativo, se consiguió evaluar los logros obtenidos en el desarrollo de competencias y análisis crítico de la realidad de los niños, niñas y adolescentes. Los resultados permiten reconocer la fotografía como una herramienta que genera más posibilidades de trabajar sobre los prejuicios de la persona que mira, dado que deja mucho más espacio a la imaginación. Por lo tanto, se construye una perspectiva hacia el desarrollo de habilidades narrativas en los beneficiarios a través de la creación de historias por medio de la fotografía, de esa manera ellos despiertan su capacidad crítica y reflexiva. Adicionalmente, la participación entre los beneficiaros sobre la base de objetivos comunes refuerza el trabajo colaborativo.

\section{PALABRAS CLAVE:}

Educomunicación. Agujero de alfiler. Fotografía Estenopeica. Alfabetización en medios.

\section{ABSTRACT}

This article wants to present the results of the "Pinhole Verte MirArte Photography Project", which main purpose is to allow vulnerable, low-income children of suburban Lima districts to open their inner look through pinhole photography. By using photography as an educational tool, the project has organized activities with the aim to develop the emotional, critical thinking and rational logic of what it means "to look". Through a qualitative work we managed to evaluate the goals obtained in the development of our objectives. The results show us the power of pinhole photography as an educational tool with huge potential to overcome the children's prejudices and to promote their imagination. Therefore, we have constructed a methodology oriented to unchain inner children's creative skill in an open collaborative workshop, by storytelling their stories using photography.

\section{KEYWORDS}

Educommunication. Pinhole. Stenopeic Photography. Media literacy. 


\section{INTRODUCCIÓN}

El presente artículo ofrece una evaluación comunicacional de una etapa del Proyecto Fotográfico Pinhole Verte MirArte. La investigación se realizó entre enero y marzo del 2013 en el distrito de Villa María del Triunfo, contando con la participación de los beneficiarios, que incluyó niños, niñas y adolescentes, sus padres y los líderes del proyecto.

El proyecto lleva más de seis años introduciendo a niños, niñas y adolescentes de 8 a 16 años de Villa María del Triunfo en el concepto y la práctica de la fotografía pinhole. Los responsables son los fotógrafos peruanos Pilar Pedraza, Morfi Jímenez, Charlotte Darwirs y Rolando Jurado, quienes son encargados de gestionar los pocos recursos recibidos, además del trabajo con voluntarios y las donaciones esporádicas como el papel fotográfico concedido por Wilhemi Monge.

Los beneficiarios fueron invitados a participar en diversas actividades para demostrar cómo ellos hacen fotos con una caja oscura y sus resultados. Posteriormente, las fotografías fueron exhibidas en varias exposiciones en Lima, así como en Colombia, Ecuador, Argentina, México, Chile y España. En cada uno de los eventos, los autores lograron cambiar sus fotografías por servicios y bienes elegidos por ellos: tratamiento dental, bicicletas, zapatillas, entre otros. Además, ganaron becas de fotografía en el Centro de la Imagen y becas de estudio en la Escuela de Arte Corriente Alterna y Euroidiomas.

La evaluación comunicacional del proyecto tiene como objetivo general conocer los logros obtenidos en el desarrollo de competencias y análisis crítico de la realidad de los beneficiarios directos a través de la fotografía. Asimismo, comprender cómo el proyecto fortaleció la identidad comunal y de qué manera fue plasmada en las fotografías haciendo uso de creatividad.

Aparici (2010) afirma que "Los medios de comunicación han permitido la familiarización de los públicos con el lenguaje de la imagen. Se consume imágenes de forma indiscriminada, sin una reflexión crítica sobre su alcance estético, formato, calidad, 
contenido, información, intenciones o ideología” (p.20). En un artículo de la revista El Educador se menciona que el pensamiento crítico ayuda a que los alumnos sean "capaces de defender y justificar sus valores intelectuales y personales, ofrecer y criticar argumentos, apreciar el punto de vista de los demás; de esta manera se prepara individuos para que gocen de una vida productiva, responsable y armoniosa” (p.5).

Frente a este contexto, surgen las preguntas: ¿cómo el proyecto Pinhole Verte MirArte ha influido en el desarrollo de competencias de los niños, niñas y adolescentes para entender el lenguaje audiovisual y crear sus propias imágenes acordes a la realidad en la que habitan?, ¿qué miran los alumnos?, ¿cómo miran? y, por lo tanto, ¿cómo se ven a ellos mismos? Además, se presentarán diferentes informes sobre el trabajo de campo llevado a cabo entre enero y marzo del 2013, realizado como parte de una investigación cualitativa en la que se emplearon técnicas como focus group a los beneficiarios, observación participante y entrevistas a profundidad a los padres y maestros.

La investigación contribuyó a identificar las competencias adquiridas por los beneficiarios, las cuales fueron:

\section{Competencias}

Desarrollar la capacidad de análisis crítico frente a cada una de las fotografías.

Utilizar la fotografía pinhole para desarrollar la creatividad y la creación de fotografías originales.

Desarrollar los aspectos cognitivo, emocional y social.

Los beneficiarios del Proyecto Pinhole Verte MirArte aprenden, a través de la fotografía, a desarrollar su pensamiento crítico frente a cada una de sus creaciones, con la condición de no conocer solamente la tecnología, sino, sobre todo, el lenguaje con el que se expresan y los contenidos de sus mensajes.

Asimismo, para el objeto de estudio de la Educomunicación audiovisual, se utilizaron contenidos propuestos a escala internacional por The United Nations Educational, Scientific and Cultural Organization (UNESCO, 2006) a través de las siguientes dimensiones:

- Impacto histórico-social: cómo influyen los medios en la sociedad actual, tanto en el ámbito individual como colectivo, cómo actúan sobre las emociones, cómo condicionan y modifican los hábitos y pautas de conducta y qué valores transmiten. 
- Agente de producción: quiénes son los productores de estos mensajes, cuáles son sus intereses, ideologías, etc.

- Alfabetización en el lenguaje audiovisual: identificar los recursos expresivos que utiliza el lenguaje audiovisual y cómo descodificarlo.

- Categoría de los medios: observar la variedad de documentos audiovisuales que existen y conocer sus características.

- Representación de los medios: cómo los medios hacen una representación determinada de la realidad.

- Alfabetización tecnológica: comprender la tecnología que hace posible la comunicación audiovisual.

\section{Relación entre educación y comunicación}

El término "educar" proviene del latín educere y educare. Educere, significa extraer lo que está adentro, e implica cuestionar, pensar, crear, hacer emerger lo que se tiene. Educare proviene de la raíz indoeuropea deuk, guiar, orientar, conducir. Por otra parte, la palabra "comunicación" proviene del término latino comunis, que significa común, por lo que comunicación será más poner en común, compartir, más que un simple transmitir ideas, información. La comunicación requiere de varias personas, es multidireccional, exige la utilización de un código compartido y facilita otros procesos, como el educativo (Martínez E., 2016).

Ambos campos perciben objetivos diferentes; sin embargo, a pesar de su ambigüedad, convergen. Por un lado, la educación y la comunicación tienen como principal meta lograr ciudadanos responsables y participativos con capacidad crítica, creadores en común de soluciones a los problemas (Martínez E., 2016).

Esta noción se ve apoyada por la Asociación de Educomunicadores, quienes consideran que la Educomunicación es un espacio teórico-práctico 
formado por las interrelaciones entre dos campos muchas veces separados: la educación y la comunicación (con especial hincapié en su vertiente mediática; un espacio de trabajo con un fin muy claro: extraer todo el potencial de la unión de estas disciplinas al servicio del desarrollo social e individual del ser humano, con la vista puesta en la consecución de un mundo más habitable para todos (Aire Comunicación, 2016).

Bajo esa premisa, hablar de comunicación y de educación como dos campos separados no tendría sentido. Como respuesta a estos cambios, existen ejemplos que reconocen aspectos importantes del proceso evolutivo de la Educomunicación.

En la década de los 50, la Educomunicación presentó las primeras experiencias. Ejemplo de esto fue cuando Célestin Freinet, un pedagogo francés, propuso la creación de revistas o periódicos producidos por los escolares. El pionero en la Educomunicación también planteó conferencias preparadas y organizadas por los alumnos para sus propios compañeros. De la misma forma, un importante grupo de autores dio aportes valiosos en el campo de la Educomunicación. Paulo Freire concebía la educación como una formación orientada a la acción, apostaba por los movimientos constructivistas que abogan por metodologías más abiertas y centradas en el alumno. Entre los teóricos destacan pedagogos como Len Masterman y David Buckingham en Reino Unido, Robyn Quin en Australia, Kathleen Tyner en Estados Unidos y Mario Kaplún en Uruguay. En España, académicos como Roberto Aparici y Agustín García han continuado con este campo de trabajo, así como el grupo español Comunicar que, desde 1986, se ha posicionado como un punto de encuentro y dinamización para quienes, en todo el mundo, plantean la importancia de la educación y la comunicación como procesos de cambio. En el proceso educativo y comunicativo, García A. (2006) afirma lo siguiente:

La Educomunicación aspira a dotar a toda persona de las competencias expresivas imprescindibles para su normal desenvolvimiento comunicativo y para el desarrollo de su creatividad. Asimismo, ofrece los instrumentos para: comprender la producción social de comunicación, saber valorar cómo funcionan las estructuras de poder, cuáles son las técnicas y los elementos expresivos que los medios manejan y poder 
apreciar los mensajes con suficiente distanciamiento crítico, minimizando los riesgos de manipulación (p.111).

Más allá de los consensos, la definición de una educación en medios suele ser motivo de debate internacional. Su significado y su objetivo de estudio pueden ser muy diferentes, según el país y los contextos social, político y cultural en los que se enmarque dicho abordaje (Mourduchowicz R., 2003, p.35).

\section{Pinhole para educar la mirada}

Los inicios de la fotografía se remontan al año 1839, desde entonces se la considera un medio trascendental para la comunicación y la expresión. Ese mismo año, Da Guerre patentó el daguerrotipo, primera técnica fotográfica. Como antecedentes de la fotografía se consideran la cámara oscura y las investigaciones sobre las sustancias fotosensibles. Alhazen (965 a 1040) fue el primero en estudiar el fenómeno de la cámara oscura:

El concepto de una cámara estenopeica o pinhole es simple: una caja con un pequeño agujero en un lado es capaz de proyectar una imagen de lo que está fuera en un lado de la caja en el interior. Quienes están familiarizados con la forma en que las cámaras modernas de trabajo se dará cuenta de que así es como funcionan las cámaras en general, pero hoy en día con la adición de lentes. Alhazen fue capaz de construir estas cámaras oscuras cientos de años antes de que el desarrollo moderno de la fotografía como la conocemos (Lost Islamic History, 2012).

En el siglo XI, científicos árabes realizaron experiencias con cámaras oscuras construidas a modo de tiendas de campaña. Cuatro siglos más tarde, las cámaras fueron dotadas de un objetivo (lente), redujeron su tamaño y se construyeron de madera con forma de caja. Este fue el origen de todas las cámaras fotográficas actuales. 
Hoy en día, la cámara pinhole es una alternativa económica para crear fotografías y plasmar experiencias. El prototipo de la cámara pinhole fue creado con materiales accesibles y en poco tiempo. García A., Criado A., Cid R. (2007) alegan que:

La actividad y uso de la cámara pinhole están dotadas de un alto interés didáctico, porque conjugan contenidos científicos y tecnológicos, que invitan a los alumnos a aprender investigando. Así, se tratan contenidos de óptica geométrica $\mathrm{y}$, en general, los relacionados con la fotografía (propagación de la luz, haces de rayos, formación de imágenes, enfoque, nitidez, iluminación); el conocimiento del ojo y el fenómeno de la visión; el umbral mínimo de sensibilidad visual, etc. También se ponen en juego procedimientos como la estimación de magnitudes, el establecimiento de relaciones trigonométricas y la semejanza de triángulos. Igualmente, se abordan problemas de tipo técnico como: lograr el oscurecimiento de la cámara, inventar diseños para conseguir diafragmas variables, o que las cámaras sean de longitud variable, etc (p.124).

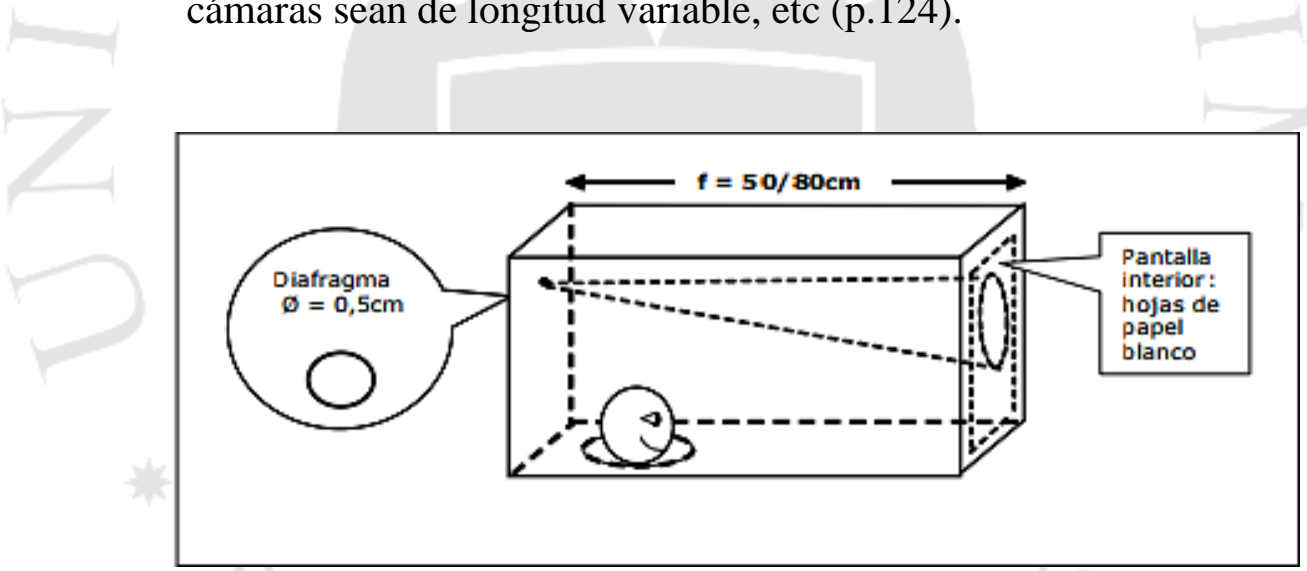

Figura 1. Prototipo de una cámara Oscura realizada con la caja de cartón.

La elección de los materiales, y el trabajo con ellos, supone utilizar el ingenio para resolver los diversos problemas que aparecen durante la construcción de la fotografía. El proceso es considerado un acto de magia y ciencia, por eso sigue consiguiendo gran relevancia a la hora de educar miradas.

Durán (2014) menciona que la fotografía estenopeica o pinhole es más que una técnica que comprende procesos físicos y químicos. El autor identifica que: 
La cámara estenopeica deja de ser simplemente un medio de reproducción de imagen y se convierte en proceso de creación donde, más que factores meramente técnicos, recrea sensaciones y comunica a través de la imagen. Es acá, cuando no sólo se maniobra un aparato mecánico, aparece al otro lado de la lente o el estenope el autor, quien obtura la cámara fotográfica y la dispone de manera intencional para apresar y fijar lo que pretende. De esta manera, se cruza el límite de la técnica y se origina la expresión (p.565).

Por esta razón, Aguaded y Martínez (1998) afirman que: "La fotografía utiliza un código específico de interpretación y construcción de la realidad de especial trascendencia en el proceso educativo. Debe ser considerada como un documento de gran valor didáctico y una privilegiada herramienta de trabajo para los alumnos" (p.52). Esto también lo ratifica Granado M., quien afirma: "Las fotografías resultan una herramienta fundamental para el proceso de educación audiovisual, y pueden ser utilizadas como meros identificadores de la realidad resultando fácil la asociación de imágenes (realidad/ficción)" (p.568).

Es necesario hablar de estas nociones vinculadas a los medios de comunicación, los cuales han permitido la familiarización de los públicos con el lenguaje de la imagen, especialmente con la fotografía. La creación de una fotografía puede plantear algunas de las siguientes interrogantes: ¿cómo realizarla?, ¿qué procedimiento utilizar?, ¿qué atributos personales proyecta el observador ante una fotografía? Frente a estas interrogantes, Melot 2010, citado en Aparici (2010:20), señala lo siguiente:

Comprender las imágenes no implica descifrarlas como jeroglíficos; en cambio es, reconocer que se trata de un artificio y que ninguna imagen ha caído jamás del cielo. Es comprender lo que se esconde en la imagen, a través de lo que muestra. Es a nuestras aspiraciones o a nuestros sueños a los que pedimos que se parezcan (p.20).

Tal consideración es apoyada por Bautista (2013), quien revela que: 
La proyección de una fotografía hecha por un humano sobre un evento que ha vivido, permite hacer visible sus intenciones, creencias, afectos $\mathrm{y}$ pensamientos, así como poder analizarla, comentarla, estudiarla y debatirla hasta llegar a comprender los significados y sentimientos que pretendía transmitir (p.73).

A través de la fotografía, los niños tienen la posibilidad de tomar conciencia de las distintas formas de representación gráfica de la realidad. Umberto Eco (1977) ya definía esta situación hace 30 años, cuando afirmaba que la civilización democrática se salvaría únicamente si hace del lenguaje de la imagen una provocación a la reflexión crítica, no una invitación a la hipnosis. Siguiendo dicha línea, nacen diversas asociaciones que reconocen y consideran a los medios de comunicación privilegiados instrumentos para el desarrollo de una educación comprometida con las demandas de la nueva sociedad.

\section{Nuevos desafíos en comunicación y educación}

Hoy en día los medios de comunicación desempeñan un papel central en la vida de los niños y de los jóvenes. Para Morduchowicz R. (2001), "los medios de comunicación y la educación son un binomio posible" (p.1).

La relación de los chicos con los medios de comunicación ha sido escasamente explorada en todo el mundo. Menor aún ha sido la preocupación por conocer el vínculo y la apropiación que hacen los chicos de sectores populares de los medios (Morduchowicz R., 2001).

En el Reino Unido, como en el resto de países anglosajones, se utiliza el término alfabetización en medios (media literacy) en lugar de educación en medios. Finalmente, esto justificaría la inclusión de la Educomunicación audiovisual dentro de la malla curricular, incorporada a partir del 2002, con el objetivo de que los estudiantes desarrollen una plena comprensión de su rol y su responsabilidad como ciudadanos en la sociedad. Por ello, la Educomunicación concentra el interés que las generaciones de hoy tienen hacia estas formas de comunicación. Asimismo, plantea retos a los educadores interesados en procurar un currículum más dinámico y pertinente, al empatar y regular el 
conocimiento de estos lenguajes dentro de un enfoque evolutivo del desarrollo. ¿Cuál es, entonces, la relación esperada entre la escuela y los medios de comunicación? ¿Qué actitud debe promover la escuela en relación con los medios? Allen y Rojas (2005) afirman que:

La escuela debe incluir prácticas para el desarrollo de habilidades tales como: la creatividad, criticidad, el pensamiento, la motivación, la atención, el descubrimiento, la asociación, la expresión, las nociones espaciales, la comprensión y la alfabetización audiovisual, entre otras, lo que llevará a enriquecer el aprendizaje holista del alumnado, que parte del complemento entre los lenguajes verbal y no verbal (p.25).

Sin embargo, en el Perú todavía no existe un campo de la "educación y comunicación”. Según Quiroz (2013):

Más allá de algunas ideas, resulta necesario sugerir a las autoridades del Ministerio de Educación, al Consejo Nacional de Educación, y otros, conversar y proponer líneas de trabajo, urge promover y esforzarnos por dotar a la educación de la posibilidad de desarrollar procesos pedagógicos interactivos y creativos. Son una necesidad imperante a la puesta de los jóvenes, como una educación acompañada de una comunicación que promueva la sorpresa y la experimentación. Visto que la formación se estructuró sobre el principio de los cursos y las materias como comportamientos estancos sometidos a pruebas de evaluación (p.159).

Una propuesta para ello es el "Aula sin muros" de McLuhan, quien hace un llamado a desarrollar nuevos procedimientos y estrategias que permitan al educando apropiarse del saber y producirlo, así dejar atrás el viejo modelo transmisivo. 


\section{METODOLOGÍA}

Este artículo, resultado de la investigación cualitativa, tiene como objetivo dar a conocer los aportes educomunicativos del Proyecto Fotográfico Pinhole Verte MirArte, el cual fomenta el desarrollo de la mirada interna de niños, niñas y adolescentes de bajos recursos por medio del concepto y la práctica de la fotografía pinhole.

Para ello, entre enero y marzo del 2013, se aplicaron las siguientes técnicas cualitativas: dos focus group con beneficiarios de entre 8 y 16 años, dos visitas de observación participante y tres entrevistas a profundidad (una a la fundadora y maestra Pilar Pedraza, otra al cofundador y maestro Morfi Jiménez y una última a Marcela, madre de un niño beneficiario).
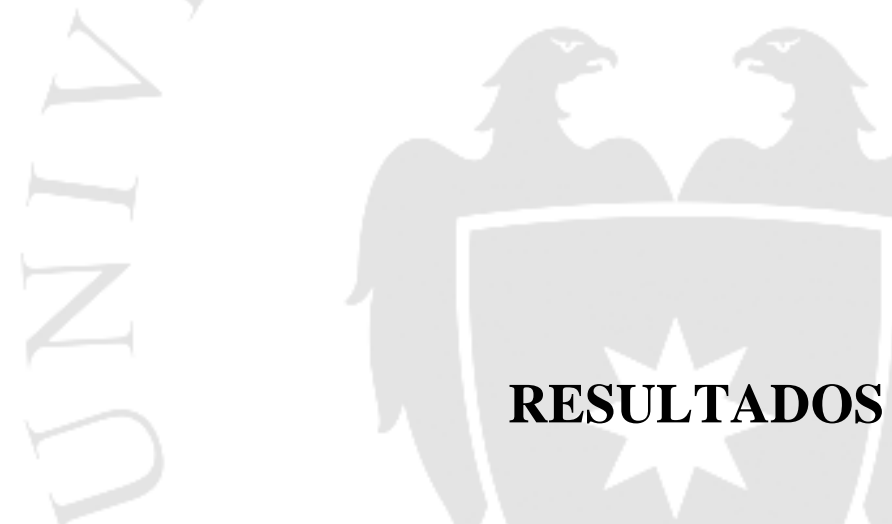

\section{El desempeño de los líderes}

La investigación constató que la fotografía es una herramienta educomunicativa utilizada para educar la mirada de los beneficiarios, reflejada en la labor que Pilar Pedraza, fundadora del proyecto, ha realizado los últimos seis años. El Proyecto Pinhole Verte MirArte consiguió trabajar a favor de chicos de escasos recursos materiales, inculcándoles que no necesitan elementos ostentosos para expresarse o desarrollase como seres humanos, que los materiales se pueden encontrar alrededor y que, en este sentido, todos son capaces de aprovechar lo que hay, por poco que parezca. De esa manera, con una caja o lata, los beneficiaros construyeron sus propias cámaras fotográficas pinhole. Pilar Pedraza afirmó que "los alumnos despiertan activamente su mirada interna, su conocimiento y sus propios anhelos, lo cual se refleja en cada una de sus fotografías". 


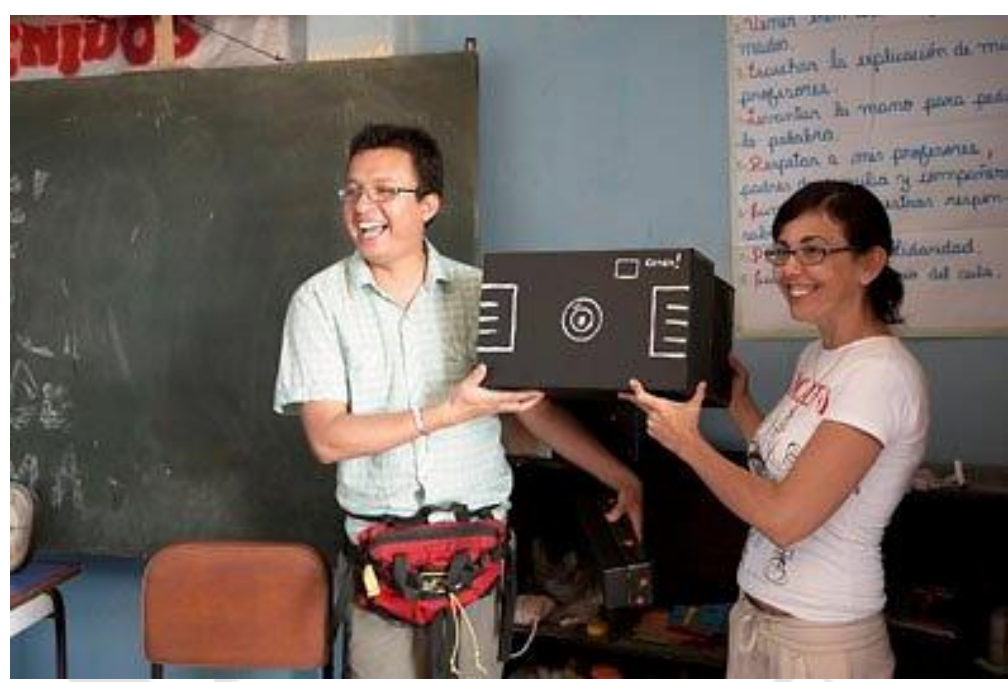

Figura 2. Morfi Jiménez y Pilar Pedraza, fotógrafos fundadores del proyecto.

Durante la observación participante, se constató cómo este proyecto fotográfico explora, en cada reunión, el lado artístico y creativo de los niños, niñas y adolescentes en condiciones de pobreza económica. En cada encuentro fotográfico se desarrolló desde el armado de las cámaras fotográficas hasta el revelado. El proceso también incluyó la preparación de los beneficiarios sobre cómo utilizar las herramientas necesarias para interpretar las fotografías. Igualmente, se les enseñó conocimientos sobre fotografía para que sean ellos quienes lleven a cabo los procedimientos que antes realizaban bajo la tutela de los maestros. De esa manera, se promovieron valores y actitudes autosuficientes e independientes.

Asimismo, en el taller, Pilar Pedraza anunció el cronograma de diferentes exposiciones de fotos donde "los alumnos participan y son ellos quienes explican cómo hicieron sus fotos, cuál fue la técnica y los mensajes que quisieron comunicar en cada una de sus fotografías". El hecho de que los alumnos sean capaces de reconocer qué efectos pueden crear, y cuáles emplean sus compañeros, es una prueba del desarrollo de su mirada crítica impulsada por la fotografía pinhole. Para lograrlo, ellos evalúan sus fotografías mediante un cuestionamiento analítico que realizan durante sus exposiciones y comentan con los asistentes.

La fundadora Pilar Pedraza resaltó que "si el proyecto sólo enseñara pinhole, de cierta forma, los limitaría y sería causal para desaprovechar alguna buena oportunidad que se presentara". Por ello, este proyecto ofrece la oportunidad a ciudadanos y 
profesionales, denominados "amigos voluntarios", para impartir conocimientos y talleres sobre cómo hacer fotos pinhole, locución radial, pintura, arte, entre otros. Uno de ellos fue el autodidacta José Chuquiere, fotógrafo del mítico TAFOS, quien enseñó cómo hacer una cámara pinhole con cajas de cartón y rollos.

Esta iniciativa crea un ambiente propicio para que los beneficiarios desarrollen habilidades narrativas, manifiesten sus emociones, expresen su creatividad, creen historias mediante fotografías y aumenten su sentimiento de seguridad.

Por medio de la observación participante, se identificó cómo se integran los beneficiarios reforzando su identidad comunal, como sucedió cuando un niño le cedió su lata de trabajo a una niña que no tenía. Estos actos son el resultado de un constante trabajo en formación de valores, por medio de la fotografía, que enriquecen su formación como ciudadanos. Como indicó Pilar Pedraza, "el proyecto busca que los chicos reconozcan que son capaces de hacer, de actuar, de razonar y de imaginar por sí mismos. Verte MirArte les enseña a caminar y abre las puertas, pero depende de ellos decidir si están dispuestos a avanzar".

En uno de los talleres, la fundadora del proyecto les recordó a los alumnos el momento en el que no recibieron un premio por su trabajo fotográfico, diciéndoles que "hay cosas en la vida que no van a salir". Si bien se puede considerar como una frase pesimista, a estos niños y adolescentes se les inculcó a través de estos mensajes el valor de la perseverancia y la constancia al nunca decir "no puedo" o "no tengo dinero, así que no puedo". Es así como se cumple uno de los objetivos principales del Proyecto Pinhole, descubrir las capacidades innatas de cada uno de los beneficiarios.

\section{Desarrollo de competencias mediante la fotografía pinhole}




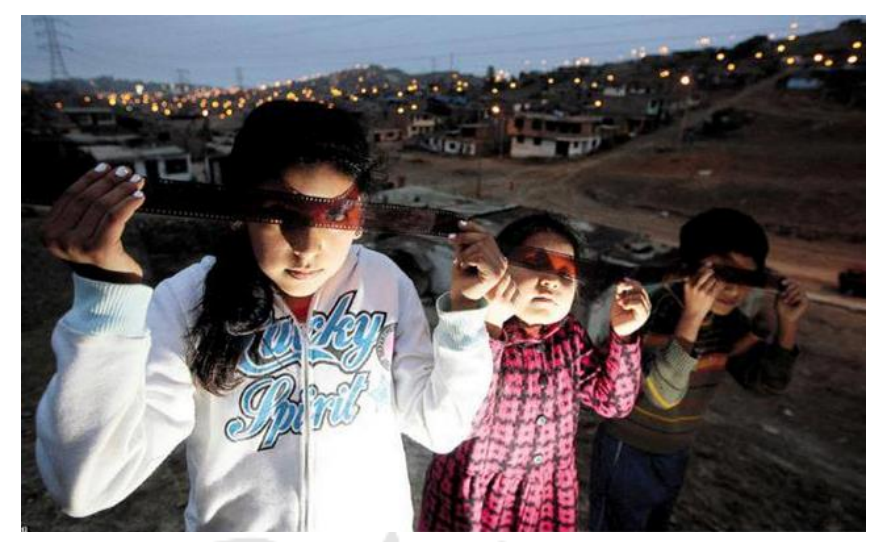

Figura 3. Fotografía Diario La República, Pinhole Verte MirArte.

En el focus group, los beneficiarios manifestaron ser conscientes de que el proyecto es uno de los pilares que ha fortalecido sus vidas, de no ser por el proyecto, “estarían viendo novelas, en Facebook o quién sabe dónde". Por ese motivo, intentaron compartir sus conocimientos con sus amigos que no son parte del proyecto, sin presionarlos porque en un primer momento ellos tuvieron dudas de enfrentarse a algo nuevo.

De igual manera, indicaron que, después de que Pilar les enseñó cómo producir una fotografía con una cámara pinhole, ellos replicaron esta experiencia en sus vidas diarias, desde una exposición en el colegio hasta en una entrevista de trabajo. Así lo comentó uno de los alumnos: "he llevado mi cámara y fotografías pinhole a mi exposición de ciencia, les he explicado a mis compañeros cuál es el procedimiento y cómo se realizan fotografías".

Por otro lado, los lugares donde los beneficiarios de Verte MirArte han tomado fotografías y realizado diferentes actividades incluyen la Plaza San Martín en el centro de Lima, el Parque Kennedy en Miraflores, el circo, la galería de Las Trece Puertas, la galería Pancho Fierro y, sin lugar a dudas, su Festival Pinhole realizado anualmente. Estos eventos pusieron en evidencia las competencias adquiridas por los beneficiarios. Como mencionó Andreé, adolescente participante, "[al proyecto] vine a descubrir mis talentos, tomar fotos y ahora me dieron la beca para estudiar arte. Sé que puedo dibujar, estudiar pintura". 
Asimismo, todos los beneficiarios comentaron que las personas a su alrededor les dicen que "no podrán llegar a ser alguien en la vida" debido a la situación precaria en la que viven. Ellos saben que, si bien no pueden cambiar las ideas que posee la sociedad, "son inmensamente ricos sin necesidad de probarlo". En ese contexto, la fotografía pinhole se convirtió en una excusa para que ellos se dieran cuenta de todo lo que pueden lograr "a través de sus pensamientos y así salir adelante". Como afirmó Guadalupe, niña participante, "[en el proyecto] aprendí que puedo ser buena en lo que no sabía serlo, comunicarme con un público, por ejemplo, porque no me gustaba hablar mucho con las personas. No hablaba."

Este desarrollo de competencias también fue reconocido por Marcela, madre de uno de los beneficiarios, que sigue el proyecto desde su inicio. Ella es una de los pocos padres de familia que acompañó a su hijo a clases y notó que "él ha cambiado su forma de ser, ha mejorado como hijo y persona, no es más como su agresivo padre, en cambio se dedica a disfrutar su niñez, ha vuelto a jugar y juntarse con sus amigos. [...] siempre tuve temor de que cuando crezca se vaya con su hermano a las pandillas, quiero verlo crecer con un mejor futuro. Mi hijo me cuenta lo nuevo que aprende y llega contento".

Si bien aún hay muchos padres a quienes no les gusta mandar a sus hijos al proyecto, la Sra. Marcela reconoció el valor del proyecto como un espacio de crecimiento para su hijo "siempre le digo que mire más allá de estos cerros, donde estamos es sinónimo de lucha, y que tenga impulso para creer, para tener sueños".

A pesar del poco apoyo de los padres, Verte MirArte ya tiene seis años y los niños que participan han aprendido mucho más. Pinhole Verte MirArte anhela que los padres se involucren en los avances de sus hijos, en la formación en valores y sean apoyo ante las dificultades. 


\section{DISCUSIÓN}

El Proyecto Pinhole Verte MirArte ha acumulado una lista de avances y logros que han beneficiado el desarrollo de competencias de los alumnos. Pero, ¿por qué continúan asistiendo?, ¿por qué a pesar de que muchos niños han superado sus expectativas aún participan de las actividades que ofrece el proyecto? Porque, como indicaron en los focus group, ellos reconocieron que el Proyecto es un espacio para adquirir conocimientos y habilidades.

Para conocer las competencias obtenidas por los beneficiarios del Proyecto Pinhole Verte MirArte, durante la investigación se aplicaron las siguientes medidas propuestas por la UNESCO sobre Educomunicación audiovisual:

\section{a) Desarrollar la capacidad de análisis crítico frente a cada una de sus fotografías:}

El Proyecto Pinhole Verte MirArte cumplió con la función de “Alfabetización en el lenguaje audiovisual" propuesto por la UNESCO. Esto fue demostrado durante las clases, cuando los beneficiarios recibieron conocimientos sobre los principios básicos de la imagen como la luz, color, ángulos, perspectiva, puntos de los mensajes visuales, entre otros, lo que permitió conocer los mecanismos que este lenguaje visual pone en funcionamiento. De esa manera, a través de la lectura de las fotografías, se motiva a los beneficiarios a desarrollar una mirada crítica, la cual se ha visto reflejada durante las exposiciones fotográficas, donde se invita a los alumnos a realizar una valoración justa y un análisis de sus fotos, explicando aspectos básicos y efectos de la fotografía pinhole en cada una de sus creaciones. Una vez más, esto refuerza su mirada crítica.

En paralelo, el Proyecto cumple la función de "Alfabetización tecnológica" durante los talleres, donde se enseña que la fotografía también explora temas de óptica, geometría, sensibilidad, entre otros contenidos considerados científicos y tecnológicos. Por ejemplo, al iniciar el taller, los profesores asesoran a los alumnos en el armado de sus cámaras: pintan de negro el recipiente (lata o caja) siguiendo el principio de la cámara oscura, cortan el aluminio en forma cuadricular para crear el diafragma y, finalmente, perforan 
el recipiente creando el estenopo (orificio por donde ingresa la luz). Tomando como base estos conocimientos técnicos, los beneficiarios aprenden a construir su cámara y comprender la función de cada elemento.

\section{b) Utilizar la fotografía Pinhole para desarrollar su creatividad y la creación de fotografías originales:}

Según el principio de "Representación de los medios" a la UNESCO le interesa saber cómo los medios manifiestan una representación determinada de la realidad. Para la aplicación de este principio, en el Proyecto Pinhole Verte MirArte, los maestros incentivan a los beneficiarios a utilizar su creatividad en la creación de sus fotografías. Si bien son personas de escasos recursos, su capacidad de imaginar no se ha limitado a su entorno en Villa María de Triunfo. Frente a esto, los beneficiarios descubren capacidades de creación y utilizan los recursos de su entorno para desarrollar sus fotografías, por ejemplo: sus compañeros, animales, las latas, sus casas, las piedras, arena, entre otros. De esa manera, cada una de sus fotos demuestra la construcción que ellos crean de su realidad con una sensibilidad muy personal.

De la misma forma, el Proyecto Pinhole Verte MirArte cumple la función de “Agente de producción” que propone la UNESCO, esto se comprobó cuando los beneficiarios crearon sus cámaras, cuando decidieron qué objetivo, paisaje o rostro fotografiar, cuando aplicaron algún efecto a sus fotos (alto contraste, desenfoque, sombras, doble exposición) cuando compartieron y disfrutaron entre amigos en los diferentes paseos o talleres que realizaron, cuando aprendieron que pueden llegar a ser mejores de lo que ya son ahora, sus sueños y anhelos se vieron reflejados en sus fotografías.

\section{c) Desarrollar los aspectos cognitivo, emocional y social:}

A partir del enfoque "Histórico - Social" que sugiere la UNESCO sobre Educomunicación audiovisual, la fotografía pinhole ha sido una herramienta importante tanto en el ámbito individual como colectivo de los beneficiarios del Proyecto Pinhole Verte MirArte al inculcarles valores. Esto se reflejó cuando, luego de pintar su primer 
cuarto oscuro, uno de los niños se ofreció a llenar los huecos de los techos, aunque no era su responsabilidad hacerlo, o cuando en todas las clases apareció ese grupo de cinco alumnos que llegaba media hora antes de empezar las clases porque no podían contener las ansias de aprender más y querían colaborar arreglando el laboratorio. La labor educadora de Pilar ha influido en su desenvolvimiento, pero quedaría reducida si no fuera por la intervención de los mismos.

Es evidente el impacto positivo que ha tenido el Proyecto Fotográfico Pinhole Verte MirArte en los beneficiarios: aprendieron a construir sus cámaras fotográficas pinhole, una novedosa herramienta didáctica inmersa del lenguaje visual; despertaron su creatividad y estimularon un proceso de aprendizaje autónomo elaborando sus propios mensajes, convirtiéndose en productores de fotografías originales; enriquecieron sus valores y capacidades; reforzaron su mirada crítica ante cada una de sus creaciones, el concepto, ideologías y mensajes que transmiten; asimismo, son capaces de compartir lo aprendido en diferentes exposiciones fotográficas, en clase y en la vida diaria, aplicando los conocimientos adquiridos en situaciones nuevas. Podemos decir, además, que los beneficiarios no sólo conocieron la tecnología que ofrece la fotografía estenopeica o pinhole, sino también, el lenguaje con el que se expresan y los contenidos de sus mensajes.

Estas experiencias, como la del Proyecto Fotográfico Pinhole Verte MirArte, inician un camino para institucionalizarse como programas y trabajan de manera aislada a un proyecto del gobierno. Aunque se trate de uno de los distritos más pobres, los niños, niñas y adolescentes no reciben ninguna ayuda, no hay un colegio cerca, no cuentan con pistas o veredas por donde transitar, ni tienen áreas verdes. Se debe recalcar que, si bien el Estado no les brinda ninguna clase de ayuda, sí lo hace el Ministerio de Cultura, entidad que ha enviado una psicóloga, obsequiado entradas para que todos los niños vayan al teatro y otorgado la titulación de "Punto de Cultura", lo que ha convertido al Proyecto en un modelo base para ser replicado en circunstancias similares debido a sus características distintivas, por ejemplo el uso de la fotografía pinhole como una herramienta didáctica a través de la cual se descubren las capacidades de creación de los alumnos, el papel de la fotografía como un sujeto activo ante la llegada de información para desarrollar una mirada crítica frente a los mensajes audiovisuales, asimismo su alto nivel educativo 
porque reúne contenidos científicos y tecnológicos que invitan a los alumnos a aprender investigando.

También, existen diferentes grupos o asociaciones que muestran interés en los beneficiarios, cuyo objetivo no solo es ir y darles dinero, sino enriquecerlos como personas integras y hábiles.

Ahora bien, ¿cómo sería si los beneficiarios tuvieran acceso a abrir sus mentes y soñar? Estos niños se vieron limitados ya que no se les brindó la posibilidad de expandir su imaginario. Se debe incentivar proyectos similares que tengan como objetivo impulsar, por zonas, proyectos de integración arraigados a las necesidades del entorno y a las propuestas de los docentes que trabajan en ellos mediante el uso de alternativas como la Educomunicación, la cual plantea retos a los educadores interesados en procurar una malla curricular escolar más dinámico y pertinente, al empatar y regular el conocimiento de estos lenguajes dentro de un enfoque evolutivo del desarrollo.

Debido a la importancia y el crecimiento acelerado de la comunicación audiovisual y de la información, se subraya la necesidad de servirse de los medios audiovisuales en todas las áreas del conocimiento y experiencia del currículum, no solo como recurso para reconstruir la base cultural que dispone cada sociedad, sino también para capacitar a niños, niñas y adolescentes para enfrentarse a un mundo donde es preciso desmitificar y también saber analizar y usar estas nuevas tecnologías para entender el entorno.

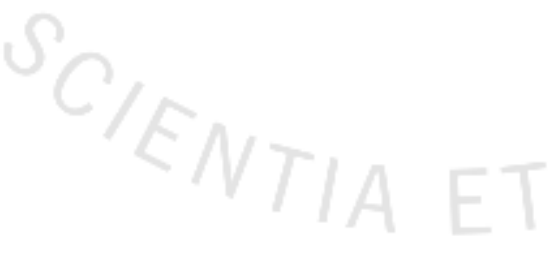

\section{REFERENCIAS}

Aire Comunicación (18 de junio del 2016) Educomunicación. Recuperado de http://www.airecomun.com/educomunicacion/que-es.html 
Allen A. y Rojas G. (2005) Enseñar a través de la fotografía. Una experiencia en primera etapa de Educación Básica. Caracas, Venezuela: Fondo Editorial UCV, Universidad Central de Venezuela.

Aparici, R. (2010) La construcción de la realidad en los medios de comunicación. Madrid, España: Fondo Editorial UNED, Universidad Nacional de Educación A Distancia.

Bautista, A. (2013). La indagación narrativa visual en la práctica educativa. Madrid, Espala: Fondo Editorial UCM, Universidad Complutense de Madrid. Páginas 69-80.

Consell de l'Audiovisual de Catalunya (2006). Recuperado de https://www.cac.cat/pfw_files/cma/recerca/quaderns_cac/Q25forum_ES.pdf

Duran D. (mayo, 2014). La fotografía estenopeica: medio, técnica y creación. UNAM, Universidad Nacional Autónoma de México. Recuperado de: http://www.revista.unam.mx/vol.15/num5/art36/

El Educador (noviembre, 2008). Lima, Perú: Grupo Editorial Norma. Recuperado de http://www.criticalthinking.org/files/educador\%2016\%2017.11\%20baja.pdf

Figura 1. Prototipo de una cámara oscura Recuperado de https://rodas5.us.es/file/21a8bfdc-20bf-fb39-d03e59b20d14ab9e/3/2_camara_oscura_SCORM.zip/images/pic001.png

Figura 2. Líderes del Proyecto Pinhole Verte MirArte. Recuperado de https://www.facebook.com/Proyecto-Fotogr\%C3\%A1fico-Pinhole-Verte-MirArte$177820945594579 /$ photos_stream

Figura 3. Beneficiarios del Proyecto Pinhole Verte MirArte. Recuperado de https://www.facebook.com/177820945594579/photos/a.292205964156076.67240.1778 20945594579/587896107920392/?type $=3 \&$ theater

García A. (2006), Educomunicación en el Siglo XXI. Fondo Editorial UNED, Universidad Nacional de Educación A Distancia. Páginas 107-126.

García A., Criado A. y Cid R. (2007). La cámara oscura en la clase de ciencia. Revista Eureka sobre Enseñanza y Divulgación de las Ciencias, Páginas 123-140. Recuperado de http://www.redalyc.org/html/920/92040108/

Granado M. (2008), La otra educación audiovisual. Comunicar. Revista científica iberoamericana de comunicación y educación, N N 3, Páginas 563-570. Recuperado de https://dialnet.unirioja.es/servlet/articulo?codigo $=4085764$ 
Lost Islamic History (20 de Junio del 2016). Recuperado de http://lostislamichistory.com/ibn-al-haytham-the-first-scientist/

Martínez E. (18 de junio del 2016) Comunicación y educación. Recuperado de http://www.uhu.es/cine.educacion/didactica/0016educomunicacion.htm

Morduchowicz, R. (mayo, 2001) Los medios de comunicación y la educación: un binomio posible. Revista Iberoamericana, $\mathrm{N}^{\mathrm{o}}$ 26. Recuperado de http://rieoei.org/rie26a05.htm

Quiroz, M. (2013) Sin Muros: Aprendizaje en la era digital. Lima: Fondo Editorial Universidad de Lima. 


\section{ANEXOS}

Fotografía 1

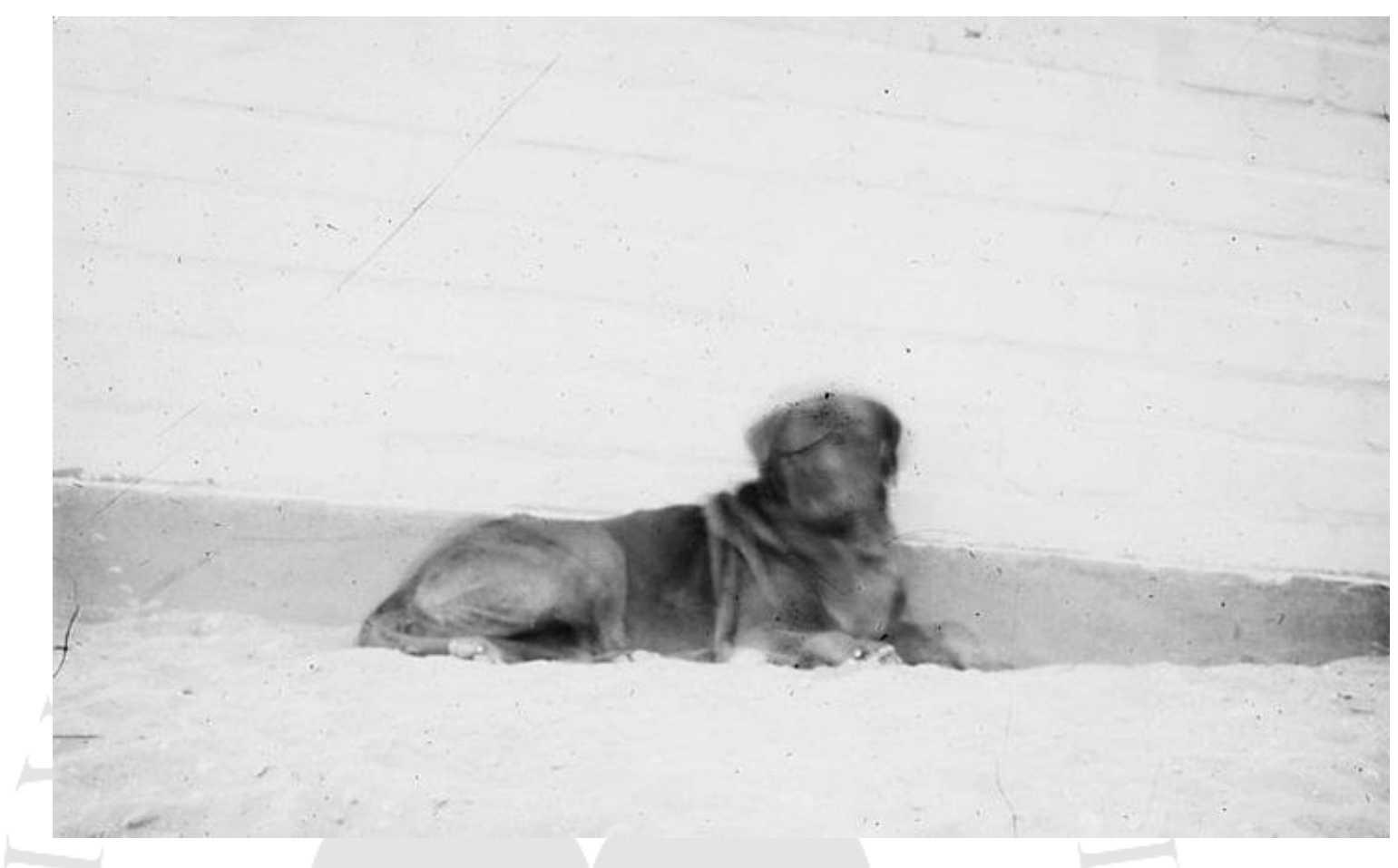

Anabel, 11 años de edad

Fotografía Pinhole

Comentario: Los animales son seres vivos muy distintos a los humanos, cuyo corazón es más puro y lindo. Los animales a diferencia de los humanos siempre están con nosotros. 
Fotografía 2

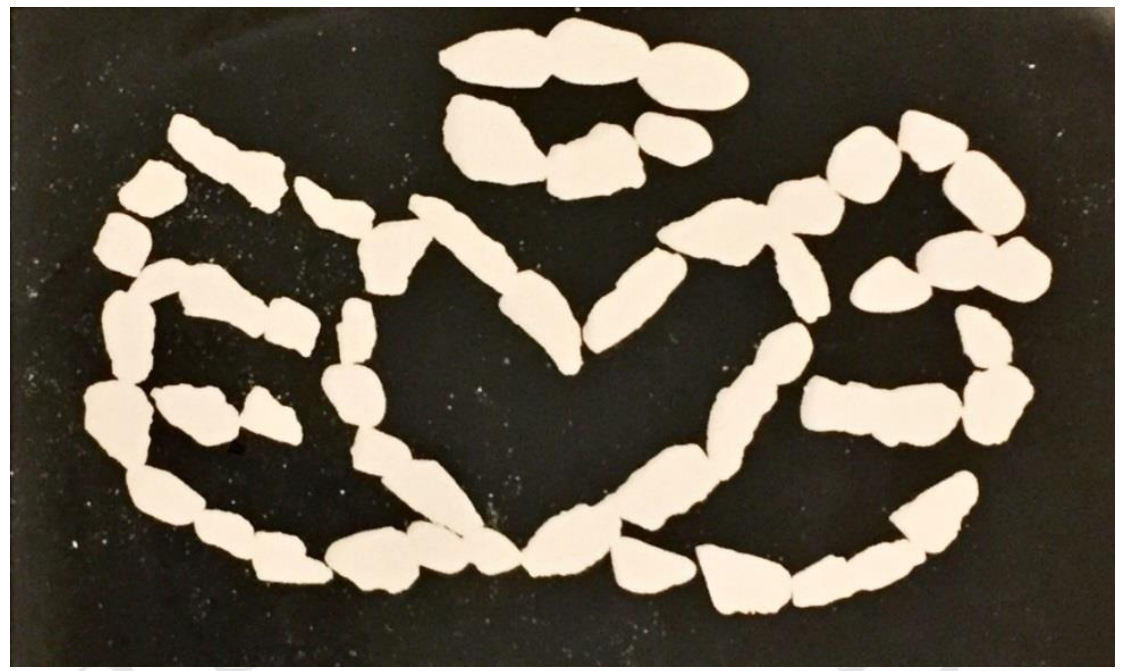

Mirko, 10 años de edad

Técnica: Fotograma realizado con piedras.

Comentario: Mi historia es triste y a la vez alegre. En la fotografía se ve que hay un corazón con alas, el corazón es mío; las alas son de mi madre porque lamentablemente falleció. Ahora ella está en el cielo como un ángel y me siento muy orgulloso de mi madre por alcanzar grandes metas y sueños. 
Fotografía 3

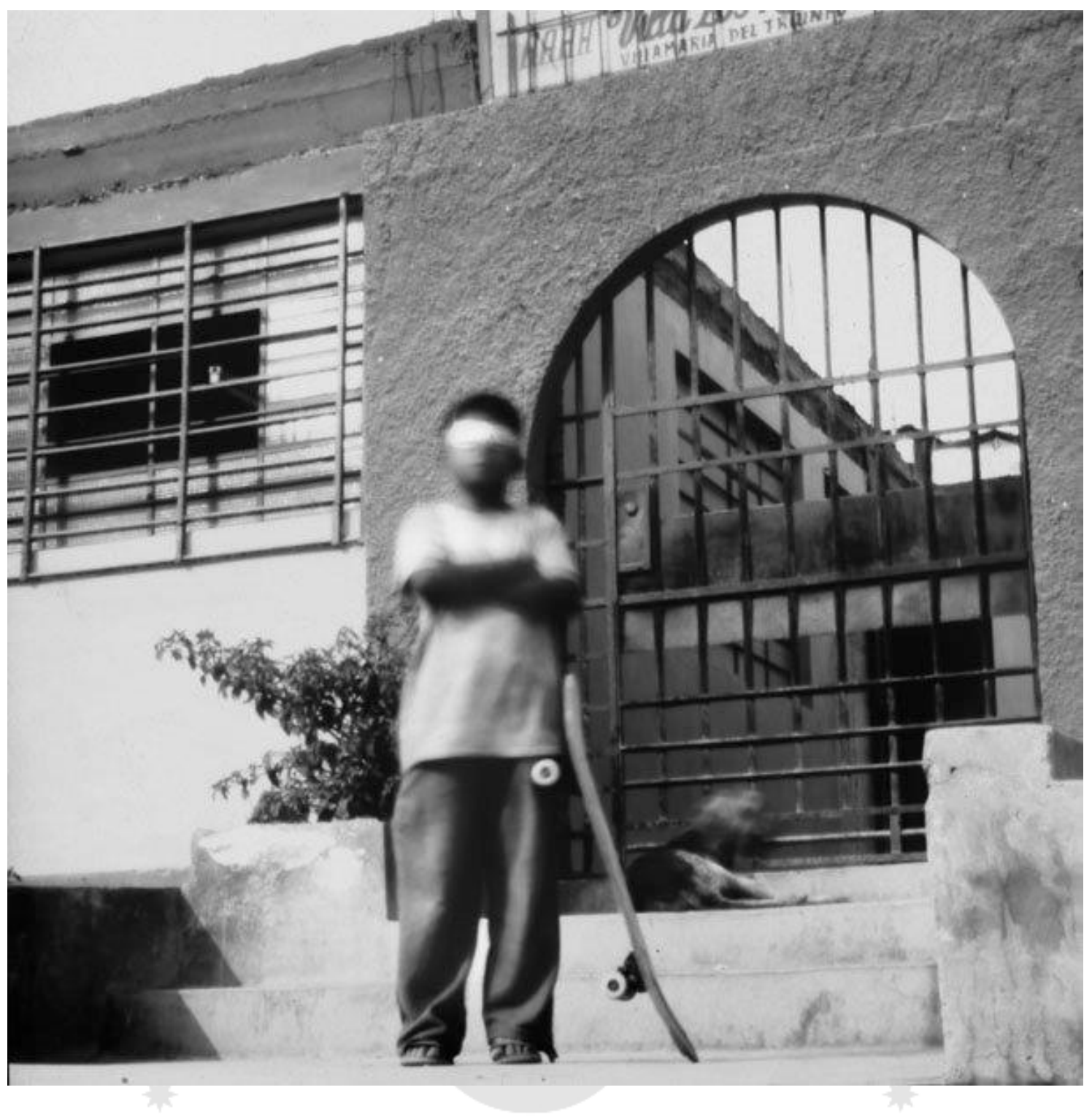

Isabel, 12 años

Fotografía Pinhole con larga exposición.

Comentario: Todos tenemos que encontrar nuestra propia personalidad, ser originales sin copiar cosas de otros. 
Fotografía 4

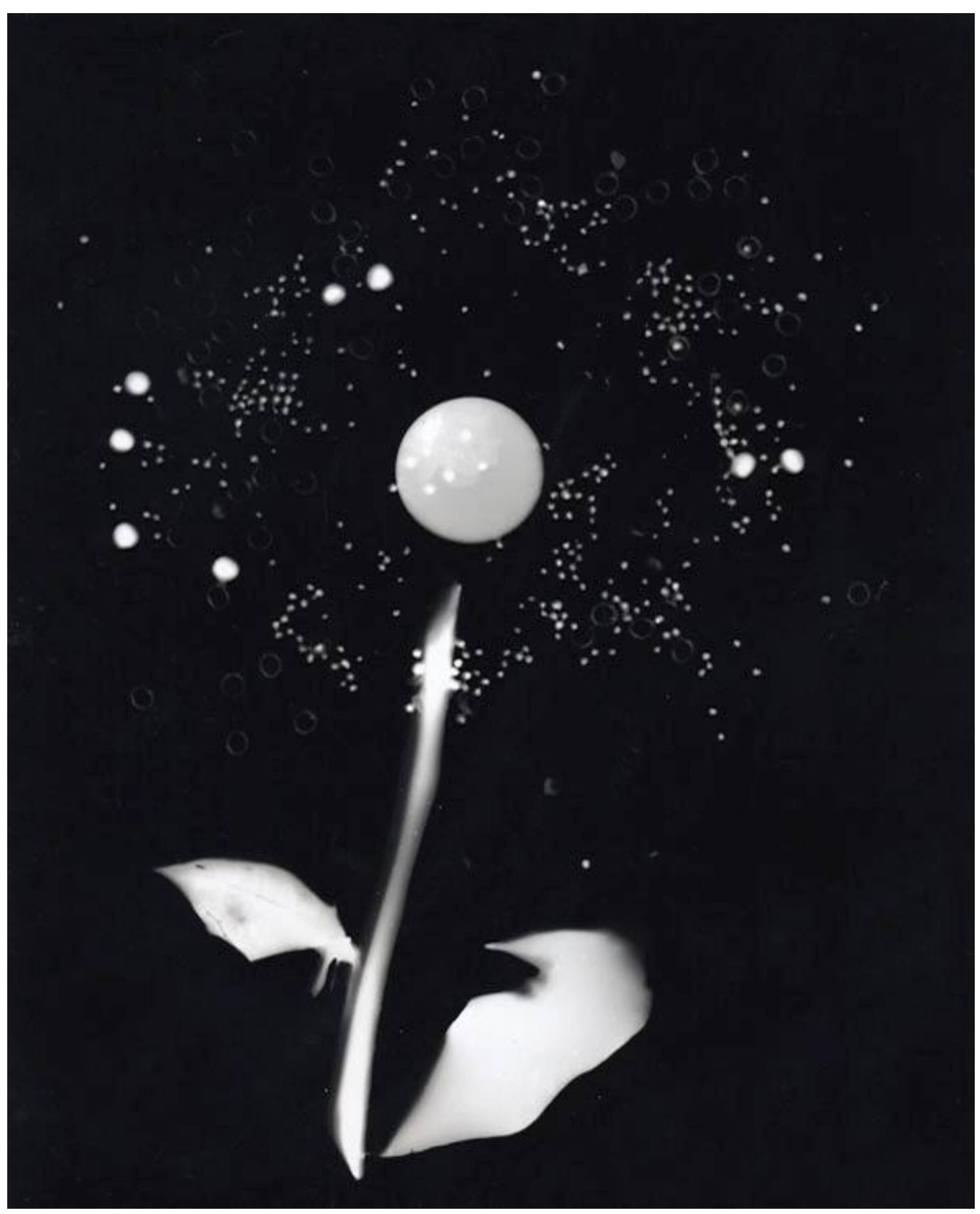

Felipe, 15 años

Técnica: Fotograma hecho con arena y hojas del parque.

Comentario: Una flor roja dormida al no ser correspondida por el ser que ama. 


\section{Reconocimientos}

El Proyecto Pinhole Verte MirArte es considerado un Punto de Cultura para el Perú a través del Ministerio de Cultura.

http://puntosdecultura.pe/puntoscultura/proyecto-fotogr\%C3\%A1fico-verte$\underline{\text { mirarte }}$

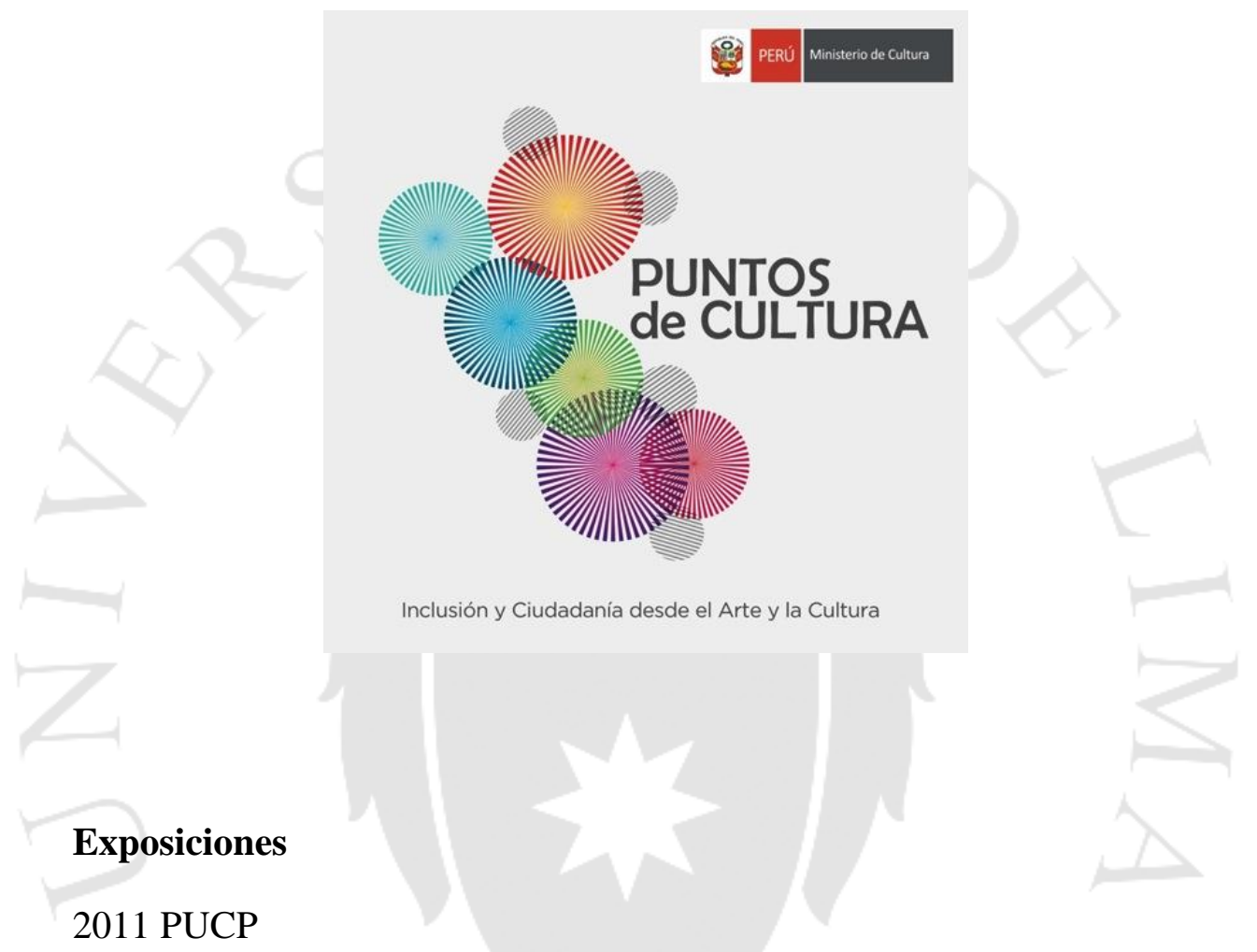

2012 La Casa de las 13 puertas, exposición colectiva, 2012

2013 Instituto de Arte Italiano:

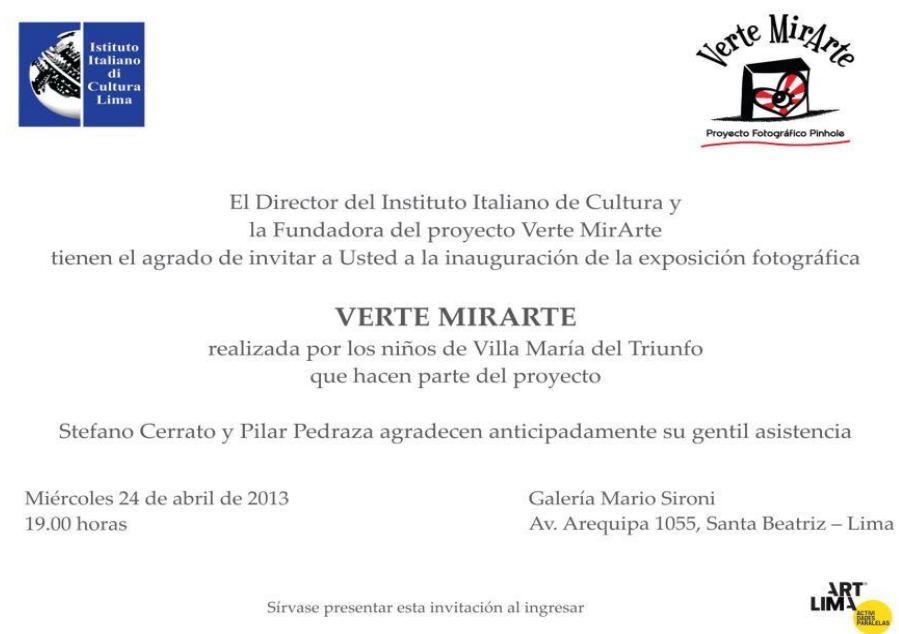


2013 Hotel Crown Plaza:

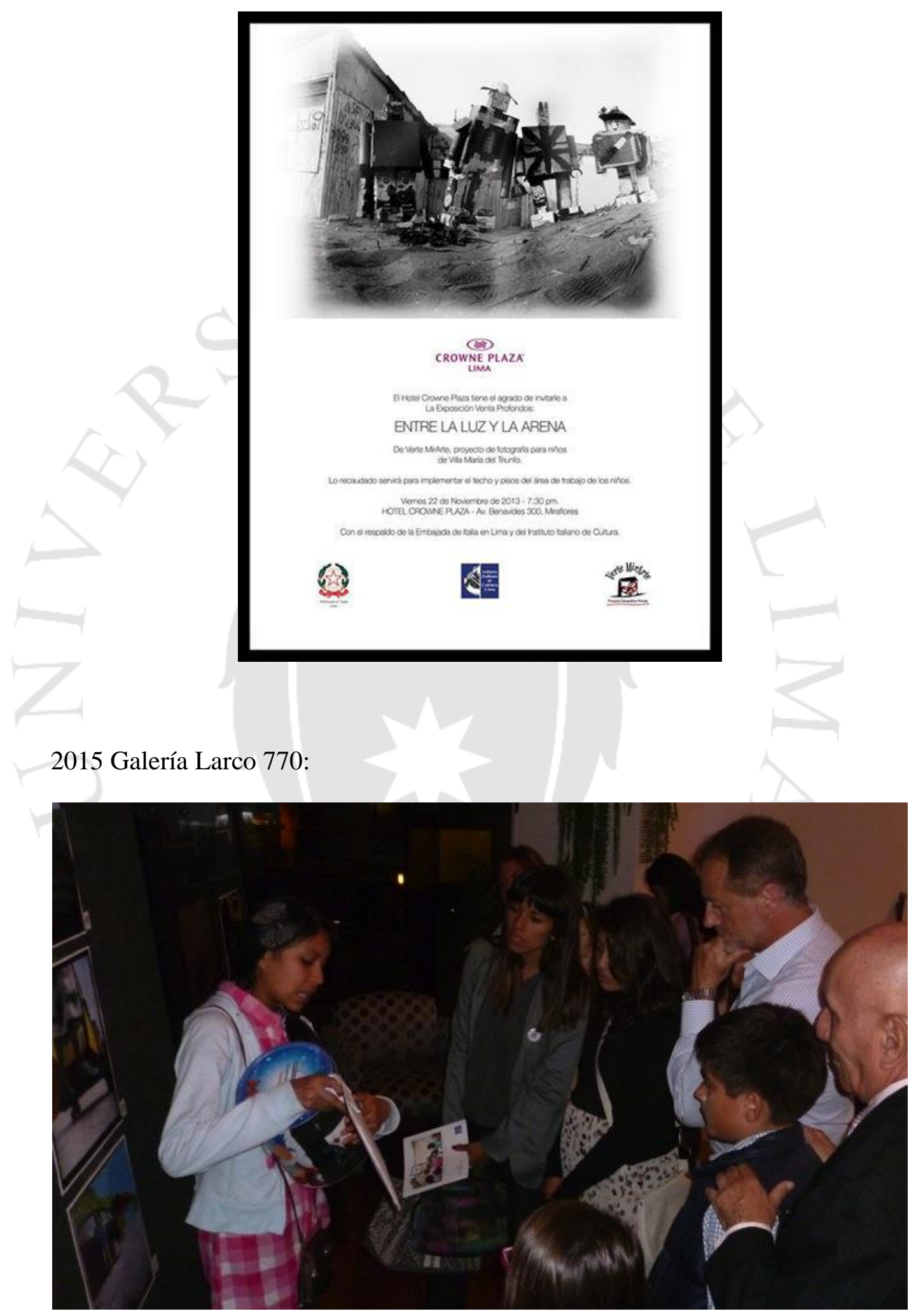




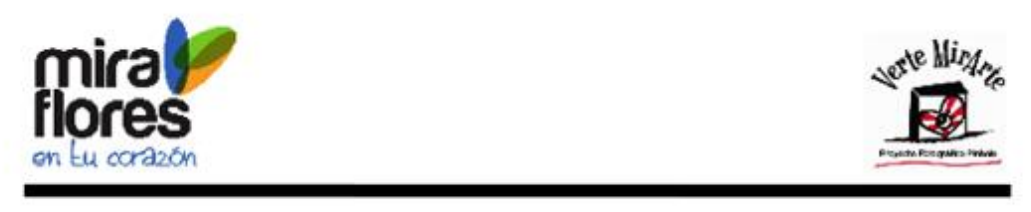

LA MUNICIPALIDAD DE MIRAFLORES TIENE EL AGRADO DE INVITAR A USTED A LA INAUGURACIÓN DE LA EXPOSICIÓN:

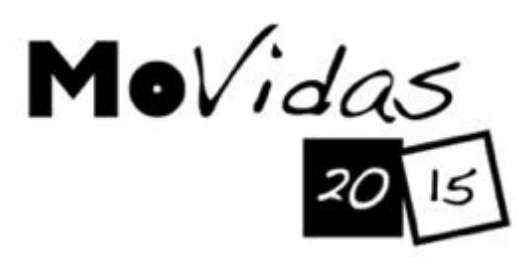

EXPOSICIÓN DEL PROYECTO FOTOGRÁFICO PINHOLE VERTE MIRARTE

\section{DICIEMBRE 9 /MIERCOLES/ 7:30 pm}

LUGAR: CENTRO CULTURAL RICARdo PALMA / Av. Larco 770, Miraflores

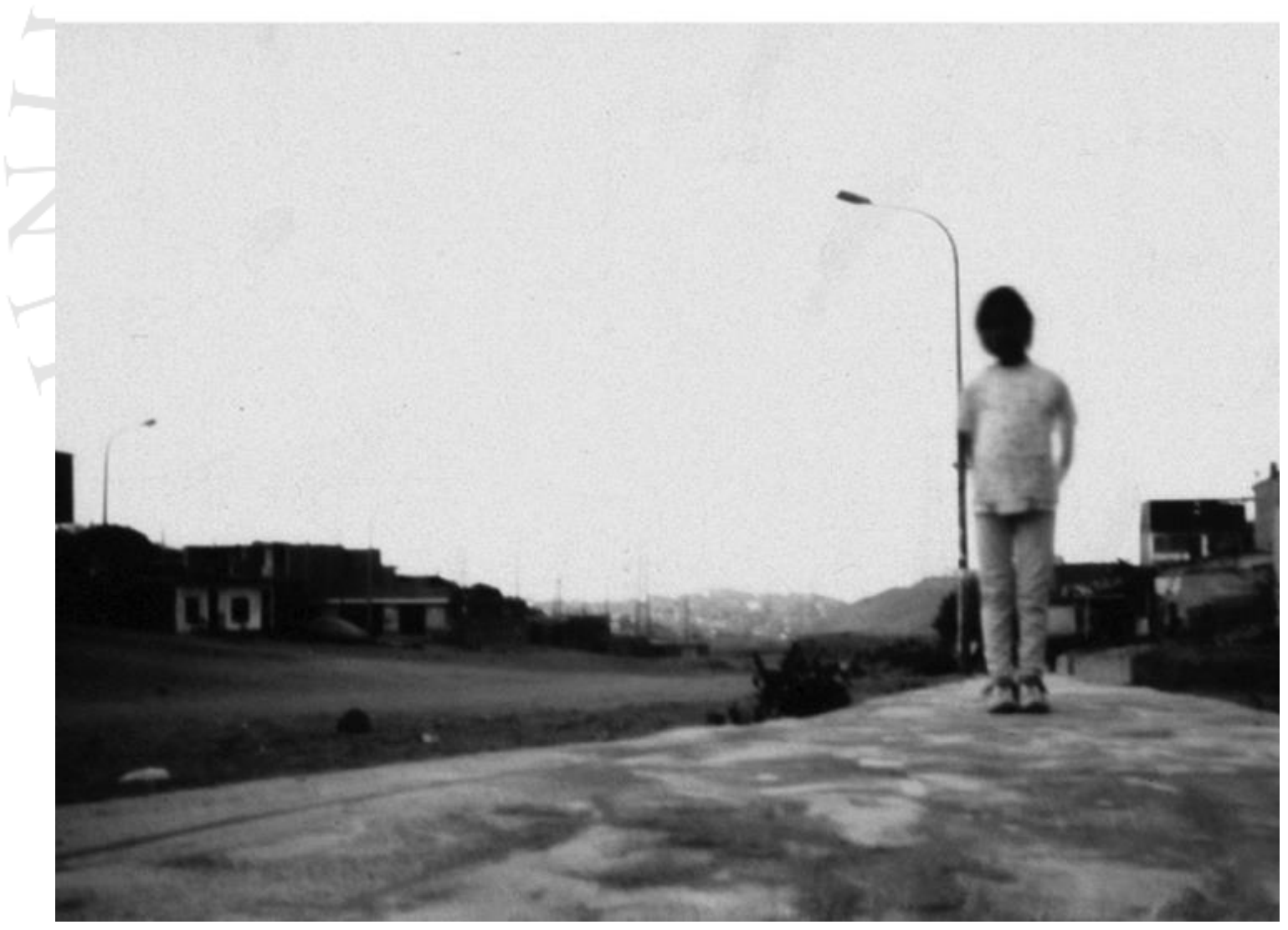


Exposiciones en varios años en México, Ecuador, Barcelona, Patagonia, Colombia, Chile, Argentina:
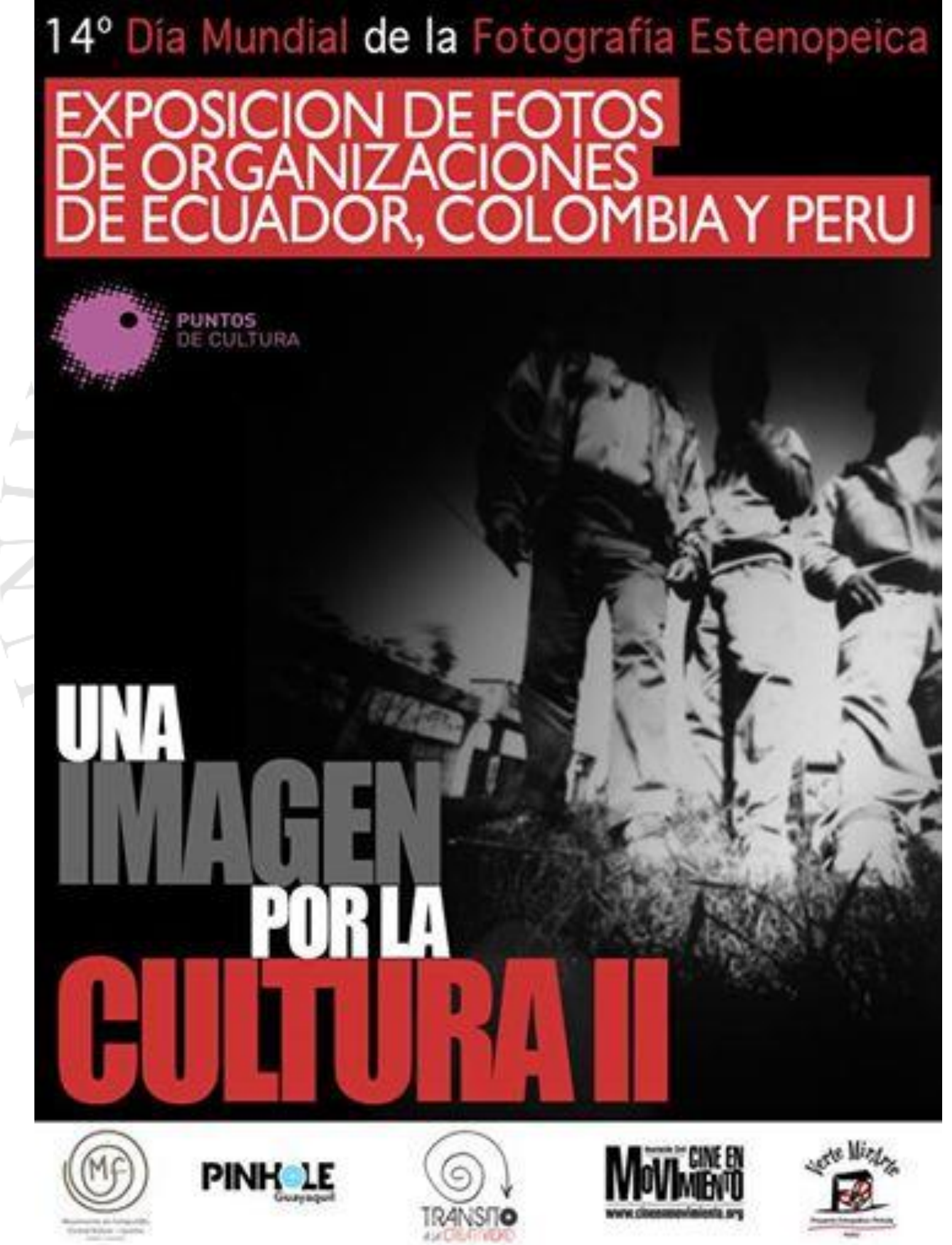


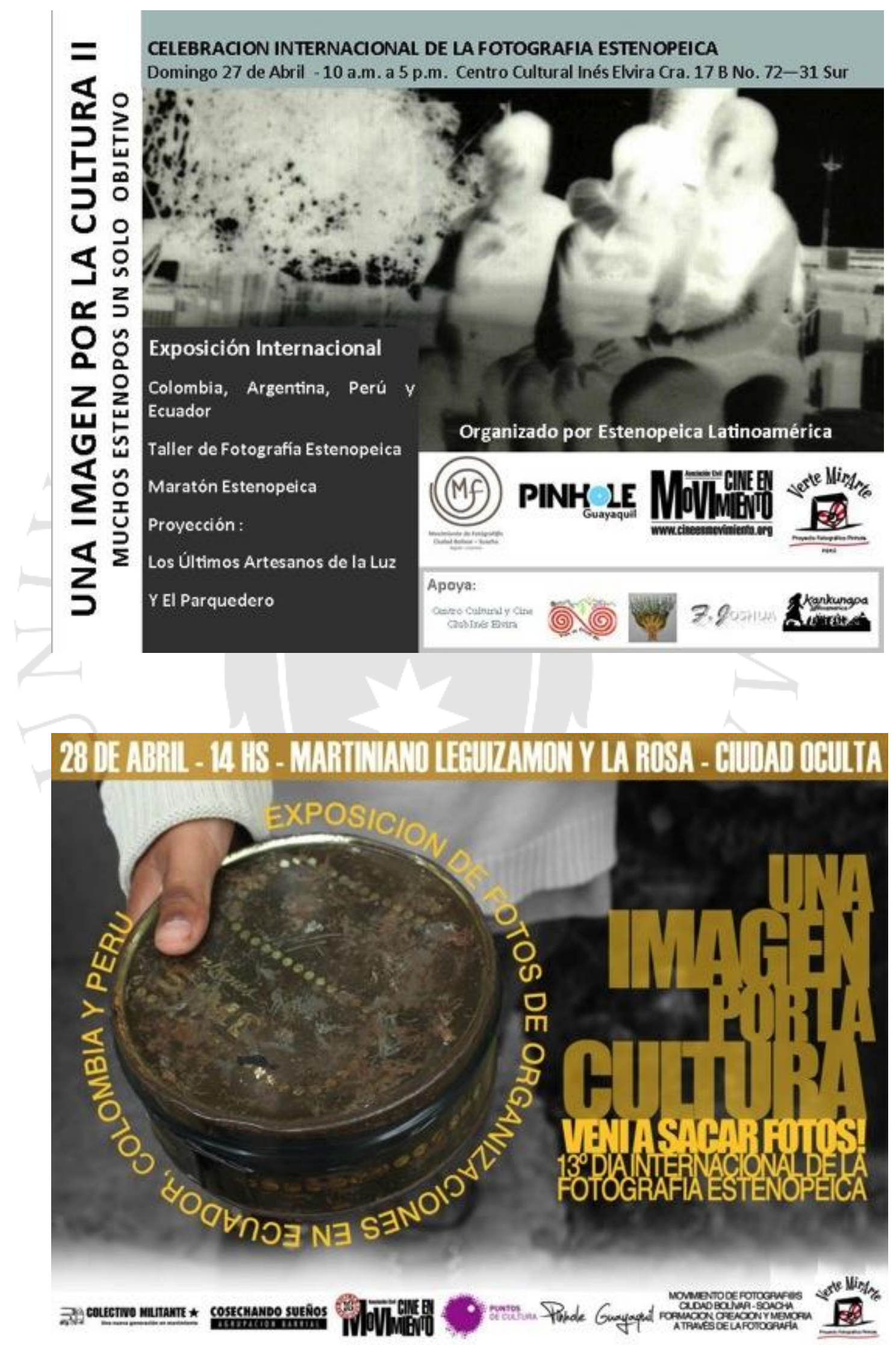




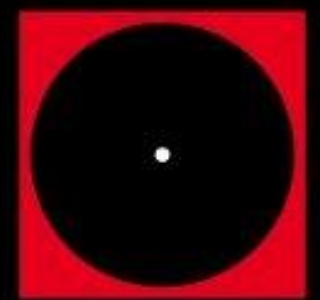

SEGUNDA MUESTRA INTERNACIONAL DE FOTOGRAFIA PINHOLE MONTERREY, NUEVO LEÓN, MÉXICO, 2013

\section{LISTA DE SELECCIONADOS}

Adrian Martinez Montiel, México

Alberto Rivera, México

Alejandra Marin, Argentina

Alejandro Flora, Argentina

Ana Ramos, España

Andrea Herrera, Chile

Astrid Rodriguez, México

Augusto Froschaver, Argentina

Colectivo Vertemirate, Perú

Ethna Guzman, México

Exequiela Goldini, Argentina

Fernando Tognis, Argentina

Guiseppe Camazca, Perú

Maki Villanueva, Perú

Hache, México

Jacques Prudhomme, Francia

Jimena Almarza, Argentina

losé Alvarez, Argentina

José Chuquivire, Peru

losé López limenez, España

loyce Dias, Brasil

Julio Reyes, Venezuela

Karina Alejandra Dotro, Argentina

Laura Fioro, Alemania

Liliana Correa, Colombia

Lorena López Centell, Argentina

Manuel Constantini, Italia

Maria de los Angeles Ponce, México

Maria Paula Pia, Argentina

Mauricio Veglio, Uruguay

Nestor Federico Velozo, Argentina

Oscar Molano, Colombia

Pablo Grinspan, Argentina

Paulo Sampaio, Portugal

Romary Daval, Francia

Selva Orfila, Argentina

Sonia Rivera, Colombia

Victor Manuel, Argentina 


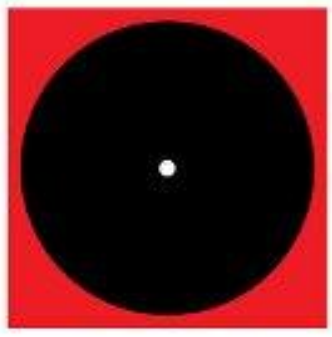

\section{Día Internacional de la Fotografía Estenopeica}

MONTERREY, NUEVO LEÓN, MÉXICO, 2012

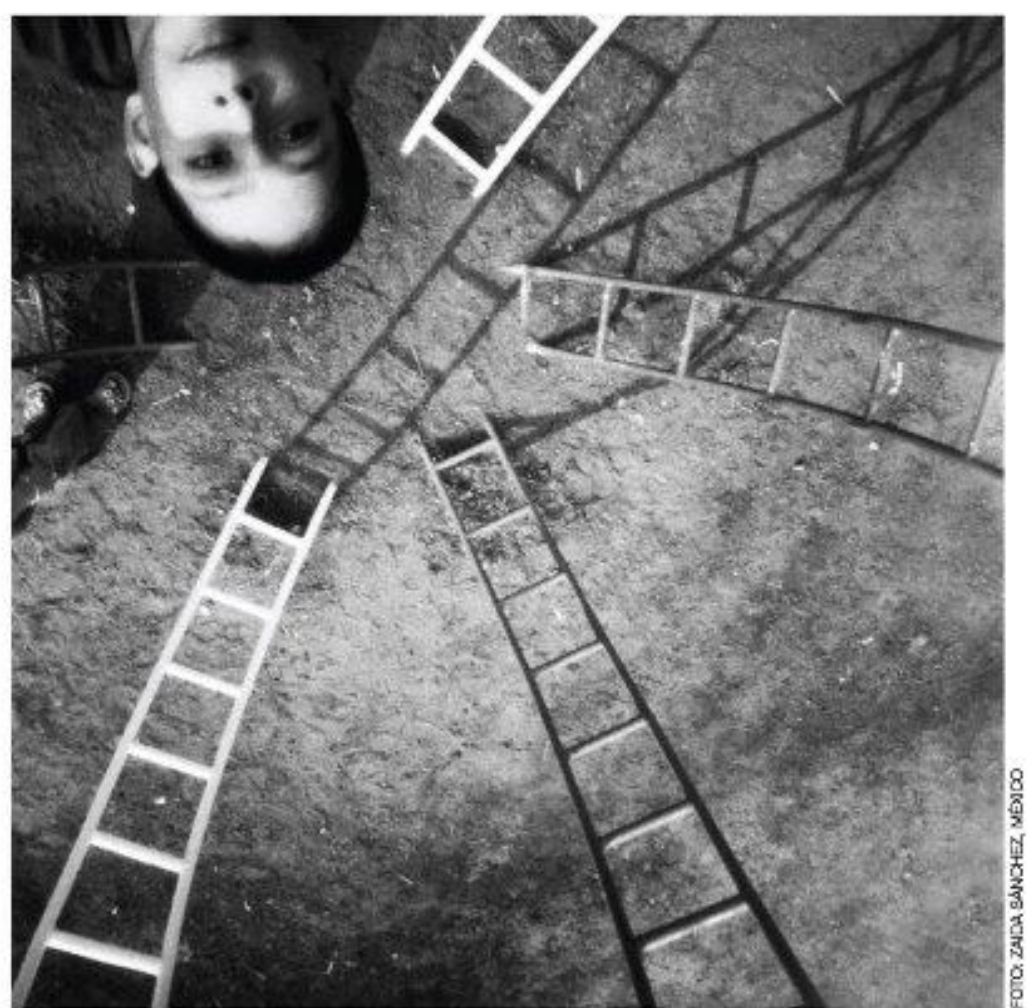

60 FOTÓGRAFOS

MÉXICO | ARGENTINA | ESPAÑA | PERÚ | PORTUGAL | COLOMBIA BÉLGICA | FRANCIA | BRASIL | VENEZUELA | CUBA | BOLIVIA

PROYECTOS INVITADOS: EL HUEQUITO DE MÉXICO Y VERTE MIRARTE DE PERÚ

INAUGURACION MIEACOLES 25 OE ARRIL DE 2012, $19: 00 \mathrm{H}$

PERMANENCLA 18 DE MAYO DE 2012 (UNES A VIEANES DE B:OD A 2J:CD H) GALERIA LEOPOLO CAPPINIEYAO

INSTITUO MEXICANO NORTEAMEAICANO DE RELACIONES CULTUAAIES HIDALGO 768 PCNIENTE, CENTRO, MONTERREY, NLL MEXUCO. T. 8C04.9090

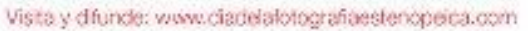

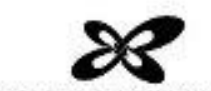

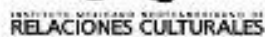

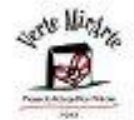


Exposición Internacional de Fotografía Estenopeica en la Feria del Libro de Bogotá, Mayo 2014:

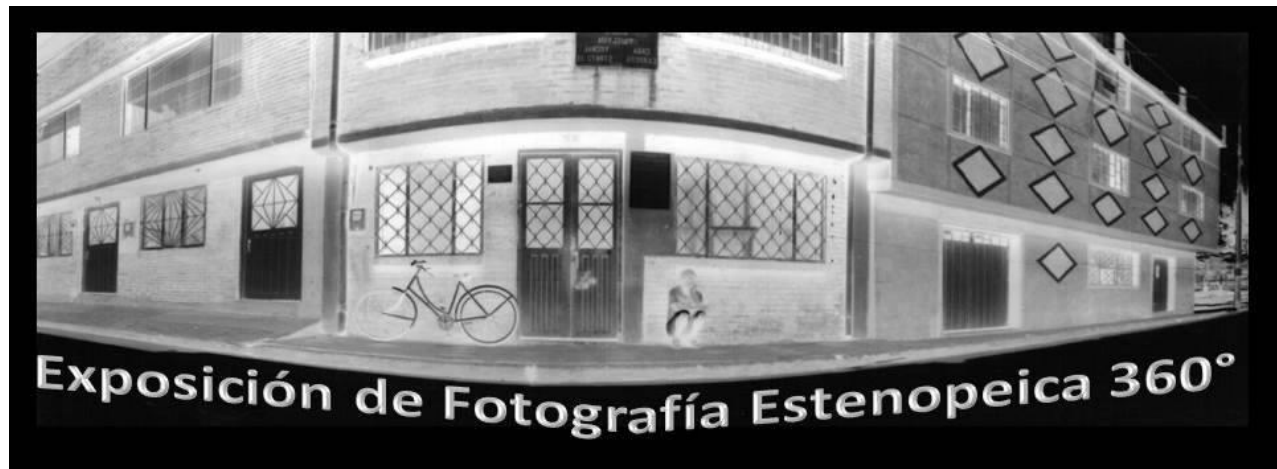

La Red Estenopeica Latinoamérica desarrolla un trabajo de formación en dicha técnica con la idea de acercar a las personas de los territorios en los que se interviene, discutir alrededor de la imagen y generar conciencia de su entorno. Es por esta razón que la muestra de este año recibe el nombre de "Fotografía Estenopeica $360^{\circ}$ "

Octubre 03 al 16 en el Teatro La Macarena Los Funámbulos, Centro de Experimentación Artística. Calle 26AN $\mathrm{AN}^{\circ}$ 4A-17 La Macarena (Bogotá, Colombia) (+571) 8054465 - 5610074 - $32142255814-3114763571$ Mayor información 316460506003125004529
Invitados Nacionales

Tunja Estenopeica, Semillero "f:18-26", Club de Medios Audiovisuales y Muralismo-Revelados y Movimiento de fotograf@s

Invitados Internacionales Proyecto Fotogáfico PINHOLE Verte Mirarte (Perú), Pinhole Guayaquil (Ecuador), Cine en Movimiento y Grupo Contraluz (Argentina), Taller Escuela Alonkura - Hualpen AGUJON espacio estenopeico (Chile). min
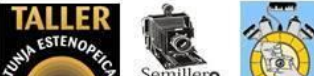

(Mf)

PINP 2 E
MoVTMENEN AGU.JON

AGUJON Contraluz

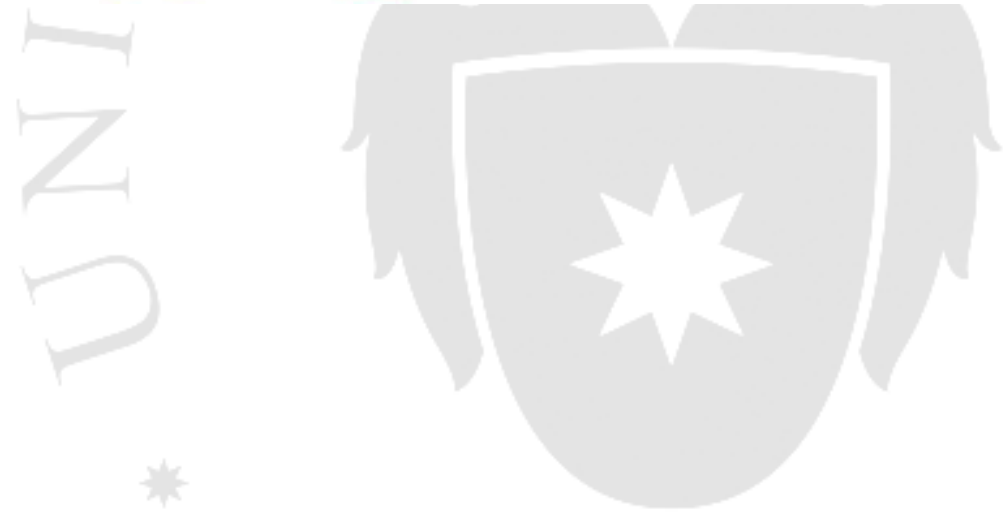

